\title{
Impact of thedevelopment of the biofuels industry on food securitytake the fuel ethanol industry as an example
}

Xu guoxia ${ }^{1}$, Ong wang ${ }^{1}$

${ }^{1}$ Nanjing University of Aeronautics and Astronautics Automation College, NankingJiangsu211100

\begin{abstract}
Asa kind of low carbon energy, biofuels have energy security, optimize energy structure, reduce carbon emissionS and other important role.However, theoretical model analysis and foreign experience shows the major food as the the raw cropsBiofuel production may produced to reclaim land and grain, the influence of the increase food, prices, and TransmissIon mechanism through international trade impact on the global food supply and prices.Changes of domestic COM and other food crops planting area of correlation analysis showed this current corn-based biofUels production scale has not impact $\mathrm{cm}$ other food crops and prices.But, as withfood crops or food crops as raw material to the expansion of biofuel productiOn, it'll inevitably impact on domestic food production and price, for this reason, this article preliminary estimates $\mathrm{THe}$ is the three kinds of biofuels production capacity influence on domestic food production and pricesFood security and industry development dual goal from industry guidance and regulation, industry technical support, theDustrial economic incentives Three aspects put forwardthe development of biofuel industry the policy system and policy.
\end{abstract}

Keywords: biofuel;Food security;Influence mechanism N

\section{UResearch Background}

\subsection{Global food security faces severe challenges}

Food is the material basis for human survival,is also a prerequisite for the continuation and development of human civilization.thenand,Sinceancient times,Human beings are always plagued by food shortages.Even in the modern age of Civilization,despite graintechnology significantly increases,But the population is growing.,arable land area decreases by year,World Food security stillfaces severe challenges.Director-Generalof the Food and Agriculture Organization of the United Nations JacquesDiouf view,affected by the international financial crisisring,to2009Year end,The total number of people threatened by starvation worldwide may increase toTenbillion.

food security is about the basic right to life for everyone,Isalso related to the state,regions and even world stability anddevelopment.in East Africa and some Asian countries,food shortages cause mass migration,social conflicts and eventurmoil;even ifin some rich and food-producing stable countries, Will cause people to panic and be dissatisfied with the food problem., and possibly Touchsocial crisis.

China is a populous country and a major food consumer,food security issues are more global and urgent.currently ItheBasic balance of grain supply and demand,The self-sufficiency rate is stable at,around.But as the population expands,,Economic Societydevelopment,consumer level rising,Thedemand for food consumption is growingby a rigid.and at the same time,arable land resource decrease by year,arable land quality declining year,The contradiction of water resource shortageis highlighted,Climate change impact increased,Regional supply and demand contradictions highlight.According to the National People's Congress Agriculture and Rural Committee data show,Theend of China's arable

\footnotetext{
Copyright $\mathbb{C}$

This is an open-access article distributed under the terms of the Creative Commons Attribution Unported License

(http://creativecommons.org/licenses/by-nc/4.0/), which permits unrestricted use, distribution, and reproduction in any medium, provided the original work is properly cited.

land about18.26billion Acres,more1997year(19.49billion Acres)reduce1.23billion Acres.National per capita
} 
arableland $1.36 \mathrm{mu}$,only for world average waterflat $40 \%$.current,China's per capita amount of water resources is about 2123 cubic meter,less than the world average of $28 \%$,agriculture produces water shortages every yearbillions of cubic meters.theexistence of these problems is becoming more and more important for our country's grain production.,food supply and demand will be in tight equilibrium for a long time,serious challenges to food security.so,How to mentionHigh-grain comprehensive production capacity,Building a food security system is a long-term issue.

\subsection{Global Energy security and environmental sustainability issues are increasingly prominent}

While people are suffering from food security problems,,Energy security is increasingly prominent.According tothe annual Global Petroleum Assessment Report oftheUnited Kingdom Petroleum Corporation("',to2003Endof,Global Proven oil reserves are11500billion barrels,to be mined at the time.year.World's proven coal mining forecast can also be minedyear.Chinamore a country with a relatively scarce energy resource per capita.According to the new round of land and resources evaluation of the national oil and gas resources, "'show(2008Year),Oil recoverable resources212billion-ton,PressAnnual Domestic output meter,available for miningYear,by actual consumption,available for miningisYear.external dependencies55\%.available to exploit natural gastrillioncubic meter,PressAnnual Domestic output meter,available for mining233Year,by actual consumption,to open117Year.external dependencies $50 \%$.China's coal remaining recoverable reserves are900billion tons,can be exploited for less than hundred years.with a further rise in per capita consumption,,Fossil Energy recoverable time will be"' without new resource discovery conditionsgreatly shortensthe, The degree of external dependencies will also increase further,Energy security issues are more pronounced.

The use of fossil fuels also brings extensive and deep environmental problems.theWorld's most severe atmospheric pollution isthegreenhouse effect of the increased carbon dioxide in the atmosphere by the "'.fossil fuel burning also brings thetheacid rain,Consequences of ozone depletion and increase of hydrocarbons, for human life and health and other biological survivalthreat.China's primary energy production and consumption structure with coalfirst,Its usage upto71\%,brought by energy consumptionThe environmental problems of are more pronounced.so,as2008year China European Union Chamber of Commerce Roundtable on Energy Working Group said,"'on the issue of energy security and environmentalSustainability, Our country is facing the largest,toughest test.

\subsection{The development of thebiofuel industry creates a new pressure on food security}

$\begin{array}{lllll}\text { Inrecent } & \text { years,to } & \text { address } & \text { global and }\end{array}$ environmentalSustainability,Renewableincluding biofuelsTheDevelopment and utilization of energy is increasingly being valuedby governments.2007yearmonth,USA New Energy bill,plan to2022Year,advanced biofuel usage in the U.S. reaches210billion gallon.European Commission plan,to2020year,market share for biodiesel to reach $12 \%$.at the push of governments,Bio-fuel industry rapid developmentshow.accordingto cleanEdgeInc,Company Statistics,2008year global production more than17billion gallon fuel ethanol and2.5billion gallon biodiesel.2008year,The world's largest producer and consumer of biofuels--Brazil50\%Auto forcar uses fuel ethanol.

2. Year,Our country has developed aRenewable Energy method,Renewable Energy medium and long term development plan,renewable energyEleven-FivePlanningA series of laws to promote renewable energy development,Planning and Policy.in biomass energy,At present, the amount of fuel ethanol used in China with grain as raw material reaches the102million ton,with cassavato produce fuel ethanol for raw materials The technology has been commercialized.with Jatrophacurcas,Pistacia chinensis etc non edible oilseeds plants as rawmaterialsBiodiesel production in5million tons.Our country has become the world's next Brazil,after the United States third largest biofuels Balcohol producer and application countries.

biofuels with increased energy supply,SecureEnergy security,Protect the environment,promote economic and socialTheImportant role of sustainable development.but at the same time, at the existing technology level, Whether for 
food orfornon-grain plants as raw materials, Thedevelopment of biofuels has created a new and enormous pressure on food security, The also causes an internationalSocial widespread interference in biofuels.International Monetary Fund(IMF,2008)think,if2015yearincreaseThe proportion of biofuels to total global fuel demand to5,,Theworld's arable land must be more than the currentexpand $15 \%$.so,countries are in the midst of the dilemma of developing biofuels and ensuring food security.acts as aA large population,can cultivate resource-hungry countries, The impact of China's development of biofuels on food security is even morecannot be ignored.

\section{1 research purposes}

The purpose of this study is to analyze the effects of the development of fuel ethanol industry with corn as raw material on China's food security,Quantitative assessment of the effects of different production scales of fuel ethanol on grain yields and prices,And from the food security and Industry issuedby theshow the dual objectives of the development of the biofuel industry regulation and incentive policy.

\subsection{Research Significance}

Accurate estimation of the impact of biofuel industry development on food security is a prerequisite for the development of the biofuel industry,is also a fundamental issue that must be emphasized in building a food security system.under existing technical conditions,biofuelsmain with corn,cassava,jatrophaCurcas,Pistacia chinensis as rawmaterial,where,due to corn raw fuel^^alcohol Industry Directtake food as raw material,Direct impact on food security,So this article takes the fuel ethanol industry as the object of study,under the assumption that fuel ethanol production technology and grain production technology are in certain conditions, key graduate fuel ethanol industryeffects on food security, To calculate the impact of different fuel ethanol industry planning scale on China's food security processdegree,and propose policy recommendations for the development of the biofuel industry in the context of food security,So for food in thesecuritysecuringand facilitating the development of the biofuels industry provide more accurate decision making and policy recommendations.so,researchhas strong practical significance.one

\section{3 theoretical significance}

Research will build fuel ethanol industry on the basis of analyzing the impact mechanism of fuel ethanol industry on food securityFood Security Impact Model,and estimate related parameters for model,to make a practice of fuel ethanol industry developmentfor theoretical references, has certain theoretical value and scientific significance.

\subsection{The basic ideas and methods of research}

The basic idea of research is:the basis for analyzing the impact mechanism of the fuel ethanol industry on food security and international experience baseon the","assumes that grain production technology and fuel ethanol production technical conditions areunchanged,Quantitative analysis of fuel ethanol industry to eachThe effect of planting area and yield of main food crops,and estimating the amount of fuel ethanol production size of maize planting surfaceThe effect of theproduct increase on the acreage and yield of major food crops,Finally, from the perspective of food securityThe policy recommendations of the ethanol industry.

\section{References}

1. International Energy Agency (IEA).World Energy Outlook [R].Paris: IEA,2013.

2. EMarkatos, etal.OptimalDesignandoperation of distributed energy system $<\mathrm{b} 26>_{\mathrm{s}}$ :applicationtoGreekresidential sector [J].Renewable Energy,2013,51:331-342.

3. MichaelAngeloA,Pedrasa,TedD,etal.A novel energy service model and optimal Scheduling Algorithm for residential distributed energy resources[J].Electric Power Systems researcH,2011,Bayi):2155-2163.

4. LiuQingrong, Lan Chunjun, Zhu Qunlog, and so on.Integrated residential area distributed energySourceSystem Import may[J].Shanghai Electric Power Academyreport,2012(6):525-528.

5. LiuQingrong,RUanYingJun, ZhuQunzhi,eTal. feasibility study of DIstributed energy system for ComprehensiveResidential area [J].Journal of Shanghai University ofElectric poweR,2012,28(6):525-528.

6. HanXinchin, on navigation..distributed to the Shanghai residential district should bewith[J].Energy 
Technology,28,29(6):374-376.

7. HanXinxiN, Yu Hang.Discussion on the Applicationtosistributed energy systemin Shanghai ResidentialdistriCT [J].Energy Technology,28,29(6):374-376.

8. zhanglei,KangZijin, Zhenglei, etc.Micro-cogeneration system[J].Save energy,

by(8):7-Ten.

9. ZhangLei, Kang ZijiN,ZhengLei,etal.Micro-CHP system[j].EnergyConservation,2004(8):7-10.

10. zhangxuyueping.talking about solar photovoltaic power generationpower supply system in residential housingMediumshouldwith[J].China Power Education,2011(9):-

11. zhag xuping.Discussion on the ApplicatIon of PV systeminresidential power system [J].China electriC power education,2011(9):-.

12. Ren Hlngbo, Wei Jungao, Ruan Yingjun.Optimal Sizing for residential CHP system [J].Applied Thermal Engineering,2008,:514-523.

13. Karialanne, Ninklas Soderholm, Kai $</$ b26 $>$ siren,etal.TeChno-economiC assessment and optim $<$ B27 $>$ iZation of StiRLing EngiNEMIcro-cogeneration systemsin residential buildings[J].Energyconversion and managemenT,2010,51(12):2635-2646.

14. Universalto.LINGO8.0foRthewindowssoftware and shoulduse[M].DayTianjin:Tianjin University Press,2004.3-26.

15. Baocheng Wan.lingo 8.0 for Windows software and application [M].Tianjin: Tianjin University Press, 2004.3-26. 